\title{
Quantitation of the histological changes found in small intestinal biopsy specimens from children with suspected coeliac disease
}

\author{
R. A. RISDON AND JEAN W. KEELING
}

From the Department of Morbid Anatomy, The Hospital for Sick Children, Great Ormond Street, London

SUMMARY The histological appearances in 85 peroral small intestinal biopsies from children have been analysed quantitatively by the method of Dunnill and Whitehead (1972). As applied to such biopsy specimens, this technique provides indices of both the mucosal volume and of the mucosal surface-to-volume ratio.

When compared with controls, 'flat' biopsies from children with untreated coeliac disease invariably showed much smaller surface-to-volume (c:lh) ratios. The mucosal volumes $(h)$ of these biopsies were, however, significantly increased. Specimens showing less marked abnormalities (socalled 'partial villous atrophy') had c:lh ratios in an intermediate range, but, like the biopsies from untreated coeliacs, $h$ values were significantly increased.

In morphologically normal biopsies correlation of surface-to-volume ratios with age showed that c:lh ratios were significantly smaller in younger children. Some of these lower $\mathrm{c}:$ lh ratios overlapped the range observed in abnormal biopsies showing partial villous atrophy. However, in the atrophic biopsies additional histological changes, such as abnormalities of the surface epithelial cells and an increased inflammatory cell infiltration of the lamina propria, were invariably present. Slight changes in biopsies from children under 2 years of age should, therefore, be interpreted cautiously, and should not necessarily be regarded as pathological on the evidence of the villous pattern alone.

The quantitative technique employed proved reproducible under normal working conditions, and its greatest practical value would appear to be in following accurately serial changes in biopsies from the same patient.

Peroral biopsy of the small intestine (Shiner, 1956) is an essential procedure in the investigation of children with suspected coeliac disease (Townley and Barnes, 1973). An effective clinical response to the exclusion of gluten from the diet can be anticipated only in the presence of typical mucosal abnormalities, which in confirmed cases of coeliac disease revert to normal on gluten withdrawal (Anderson, 1960). Treatment with a gluten-free diet in this condition is currently recommended throughout life (Young and Pringle, 1971). This is because the underlying sensitivity to dietary gluten is now generally regarded as permanent (Anderson, Gracey, and Burke, 1972). It is also felt that adherence to such a diet might lessen the risk of intestinal lymphoma, which has an increased incidence in adults with gluten-sensitive enteropathy (Harris, Cooke, Thomson, and Waterhouse, 1967; Whitehead, 1971).

Received for publication 25 September 1973.
Thus the histological diagnosis of coeliac disease in children has far-reaching significance for the patient. In confirming this diagnosis it is necessary to demonstrate not only a mucosal abnormality but also the return to a normal morphology on withdrawal of dietary gluten (Meeuwisse, 1970). The primary need, however, is for an accurate interpretation of the intestinal biopsy appearances, so that any abnormalities may be reliably recognized. Since the principal histological abnormalities encountered are atrophy, or varying degrees of blunting of the intestinal villi, one way in which diagnostic accuracy might be improved is by the application of objective morphometric techniques for the assessment of the changes found rather than relying solely on subjective interpretation.

The most recent technique evolved for this purpose is that of Dunnill and Whitehead (1972). Their method requires the determination of an index related to the surface-to-volume ratio of the mucosa, 


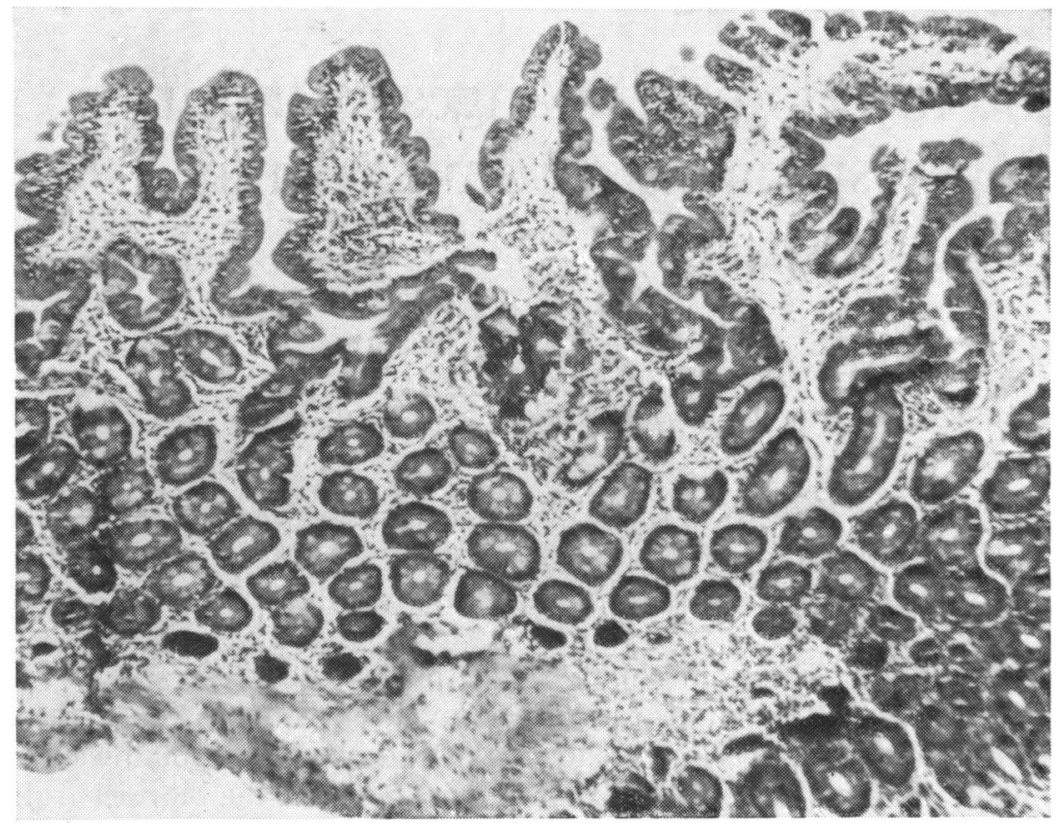

Fig 1 Tangentially cut biopsy. The crypts of Lieberkuhn are cut in cross section. $H E \times 15$.

and also allows an assessment of mucosal volume. Dunhill and Whitehead considered their technique to be superior to previous attempts at quantitative analysis of small intestinal biopsies based on, for example, measurement of villous height, mucosal thickness, crypt depth, and surface area (Rubin, Brandborg, Phelps, Taylor, Murray, Stemler, Howry, and Volwiler, 1960; Thurlbeck, Benson, and Dudley,
1960; Madanagopalan, Shiner, and Rowe, 1965; Stewart, Pollock, Hoffbrand, Mollin, and Booth, 1967), since it overcomes many of the technical difficulties inherent in these earlier methods.

In the present study we have applied the method described by Dunnill and Whitehead to the analysis of a number of small intestinal biopsies from children, many of whom were suspected of having

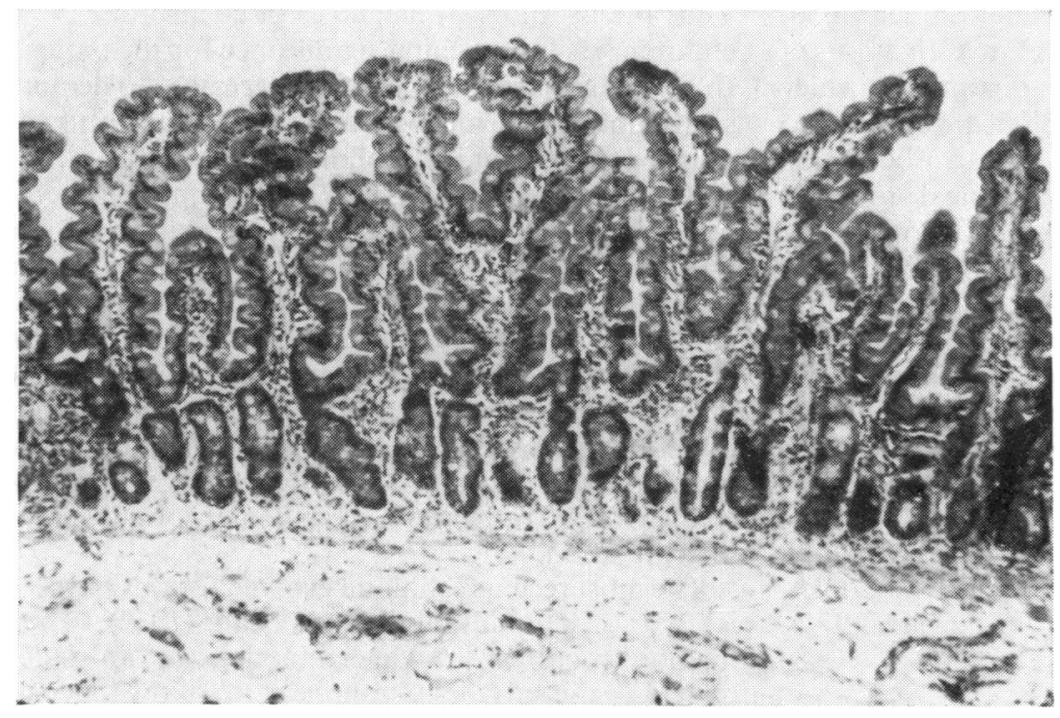

Fig 2 Correctly orientated biopsy. The crypts of Lieberkuhn are cut longitudinally. $H E \times 15$. 
coeliac disease. The results of these quantitative assessments of the biopsy appearances have been related to the clinical findings in these children.

\section{Materials and Methods}

Sections were reviewed of all the 122 small intestinal biopsies performed at the Hospital for Sick Children, Great Ormond Street, between June 1970 and March 1973. Thirty-seven of the biopsies were rejected either because they were considered to be inadequate in size or because the sections were tangentially cut. Only those biopsies were considered in which the plane of section was perpendicular to the luminal surface, as judged by the fact that the crypts of Lieberkuhn were cut longitudinally and not in cross section (figs 1 and 2). Altogether 85 biopsies proved satisfactory for assessment. The case records of the 82 children from whom these biopsies were obtained were examined in order to correlate the clinical and histopathological findings. The patients fell into three groups. The main clinical and pathological findings are shown in table I. Group I included patients who had been biopsied as part of the investigation of short stature or failure to thrive or because of a history of diarrhoea. Since in none of them was there any investigational evidence of malabsorption, and since their biopsies showed no subjective histological abnormalities, they were regarded as 'normals'.

Group II consisted of patients with untreated coeliac disease all of whom had intestinal biopsies which showed complete villous atrophy. All but two of these patients had never received a gluten-free diet, and the remaining two had not been given such a diet for some time before the date of biopsy.

Group III was a miscellaneous category of patients biopsied for various unrelated reasons as shown in table I.

\section{Intestinal Biopsies}

Peroral biopsies of the small intestinal mucosa were performed under fluoroscopic control using a Crosby capsule. The specimens were taken immediately distal to the ligament of Treitz. On being released from the capsule,each biopsy was orientated with the minimum of handling onto a piece of card and examined with the aid of a dissecting microscope. A description of the mucosal appearance was recorded in every case, and in some instances the dissecting microscopic appearances were photographed. The biopsies were fixed in buffered $10 \%$ formalin ( $\mathrm{pH} \mathrm{7.0)}$ ) for $24 \mathrm{hr}$, processed, and embedded in paraffin wax. Embedding was performed with the aid of a large magnifying lens to ensure that sections were cut perpendicular to the mucosal surface. The sections were cut at $5 \mu$ thickness, and stained by Ehrlich's haematoxylin and eosin and by the periodic acid-Schiff method. Several sections were attached to each slide so that between 10 and 20 sections were available for examination from each biopsy.

\begin{tabular}{|c|c|c|c|c|c|c|c|c|}
\hline \multirow[t]{2}{*}{ Group } & \multicolumn{3}{|c|}{ Patients } & \multirow{2}{*}{$\begin{array}{l}\text { Investigational } \\
\text { Evidence of } \\
\text { Malabsorption }\end{array}$} & \multirow{2}{*}{$\begin{array}{l}\text { Age (mth) } \\
\text { Range } \\
\text { (median) }\end{array}$} & \multirow[t]{2}{*}{ Indication for Biopsy } & \multirow{2}{*}{$\begin{array}{l}\text { No. of } \\
\text { Biopsies }\end{array}$} & \multirow{2}{*}{$\begin{array}{l}\text { Histological } \\
\text { Abnormalities }\end{array}$} \\
\hline & $\begin{array}{l}\text { Total } \\
\text { No. }\end{array}$ & $\boldsymbol{M}$ & $F$ & & & & & \\
\hline I & 36 & 23 & 13 & Absent & $7-166(51)$ & $\begin{array}{l}\text { Short stature or failure to thrive (18) } \\
\text { Diarrhoea (18) }\end{array}$ & 37 & None \\
\hline II & 29 & 13 & 16 & $\begin{array}{l}\text { Present (24) } \\
\text { Absent (6) }\end{array}$ & $5-150(45)$ & $\begin{array}{l}\text { Clinical history suggestive of coeliac } \\
\text { disease }\end{array}$ & 30 & $\begin{array}{l}\text { Complete villous } \\
\text { atrophy }\end{array}$ \\
\hline \multirow[t]{10}{*}{ III } & 3 & 2 & 1 & Present & $96-157$ & Malabsorption, no definite diagnosis & 3 & None \\
\hline & 2 & 1 & 1 & Absent & $137-144$ & $\begin{array}{l}\text { Coeliac disease, given short course of } \\
\text { gluten as a 'gluten challenge' after long } \\
\text { periods on gluten-free diet }\end{array}$ & 3 & $\begin{array}{l}\text { Partial villous } \\
\text { atrophy }\end{array}$ \\
\hline & 4 & 4 & 0 & Absent & $42-164$ & $\begin{array}{l}\text { Clinically diagnosed coeliacs biopsied on a } \\
\text { gluten-free diet }\end{array}$ & 4 & None \\
\hline & 1 & 0 & 1 & Present & 91 & Enterokinase deficiency & 1 & $\begin{array}{l}\text { Fusion of villi; } \\
\text { epithelial changes }\end{array}$ \\
\hline & 1 & 0 & 1 & Present & 113 & Megaloblastic anaemia ? tropical sprue & 1 & $\begin{array}{l}\text { Severe partial villous } \\
\text { atrophy }\end{array}$ \\
\hline & 1 & 1 & 0 & Present & 125 & Polyarthritis; immunological deficiency & 1 & $\begin{array}{l}\text { Fusion of villi; } \\
\text { epithelial changes }\end{array}$ \\
\hline & 2 & 1 & 1 & Present & $49-112$ & $\begin{array}{l}\text { Cystic fibrosis (2); associated coeliac } \\
\text { disease (1) }\end{array}$ & 2 & $\begin{array}{l}\text { None (1); partial } \\
\text { villous atrophy (1) }\end{array}$ \\
\hline & 1 & 0 & 1 & Absent & 101 & $\begin{array}{l}\text { Hypophosphataemic vitamin D-resistant } \\
\text { rickets }\end{array}$ & 1 & None \\
\hline & 1 & 0 & 1 & Present & 6 & ? Milk allergy & 1 & $\begin{array}{l}\text { Partial villous } \\
\text { atrophy }\end{array}$ \\
\hline & 1 & 0 & 1 & Absent & 100 & $\begin{array}{l}\text { Past history of ? coeliac disease; normal } \\
\text { diet } 40 \mathrm{mth}\end{array}$ & 1 & $\begin{array}{l}\text { Partial villous } \\
\text { atrophy }\end{array}$ \\
\hline
\end{tabular}




\section{Histological Assessment}

We have followed closely the method of analysing the histological changes in small intestinal biopsy specimens described by Dunnill and Whitehead (1972). Like these authors, we employed a template of 15 lines of equal length which connect the vertices of a regular hexagonal point network. The template was drawn according to the specifications of Weibel (1963) on an eye-piece graticule prepared for us by Graticules Ltd. This was inserted into the eye-piece of a Zeiss photomicroscope so that the image of the graticule was superimposed upon that of the section (fig 3). The objective and ocular combination of the microscope yielded a magnification of $\times 128$, and this was kept constant throughout the study. At this magnification the length (l) of each line cast on the section was $1.4 \times 10^{-2} \mathrm{~cm}$. The section was orientated so that it lay centrally in the vertical axis of the microscopic field and the most lateral of the lines on the graticule was superimposed on the muscularis mucosae. The other lines then fell at random over the biopsy. A cut (c) was counted where a line fell over the epithelium covering the mucosal surface, and a hit (h) was counted where the end of a line fell over the mucosal tissue between the covering epithelium and the muscularis mucosae. This tissue

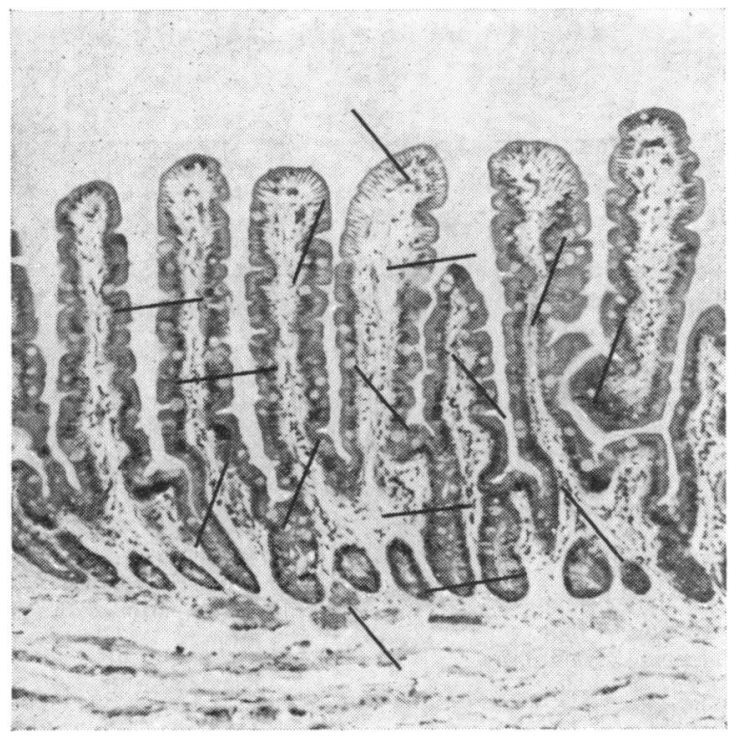

Fig 3 A template of 15 lines of equal length arranged according to the specifications of Weibel (1963). They are superimposed over a section of a normal biopsy. 'Hits' are counted where the endpoints of the lines lie over the mucosa; 'cuts' are counted where the lines cross the surface epithelium. $H E \times 15$. included the lamina propria and the mucosal glands and crypts. The numbers of hits (h) and of cuts (c) were recorded. When the first microscopic field had been counted, the slide was moved with the aid of the mechanical stage until the adjacent field was in view and this was then counted in turn. This process was repeated until a sufficient number of fields had been counted so that the value for $h$ was approximately 200. The number of fields examined was recorded.

The index $c: l h$, which is related to the surface-tovolume ratio, was calculated for each biopsy specimen as an indication of the complexity of the villous pattern. The mean number of hits per microscopic field examined $(\bar{h})$ was also determined since this is proportional to the mucosal volume.

We both determined the ratio $c: 1 h$ and $\bar{h}$ independently in each of the 85 biopsies studied, without knowledge of the origin of the specimen or of the clinical details. For each biopsy mean values were calculated for these two determinations. In fact, highly significant correlations were observed between our two sets of results (for c:lh, $r=0.99, P<0.001$; and for $\bar{h}, r=0.96, P<0.001)$ and the greatest

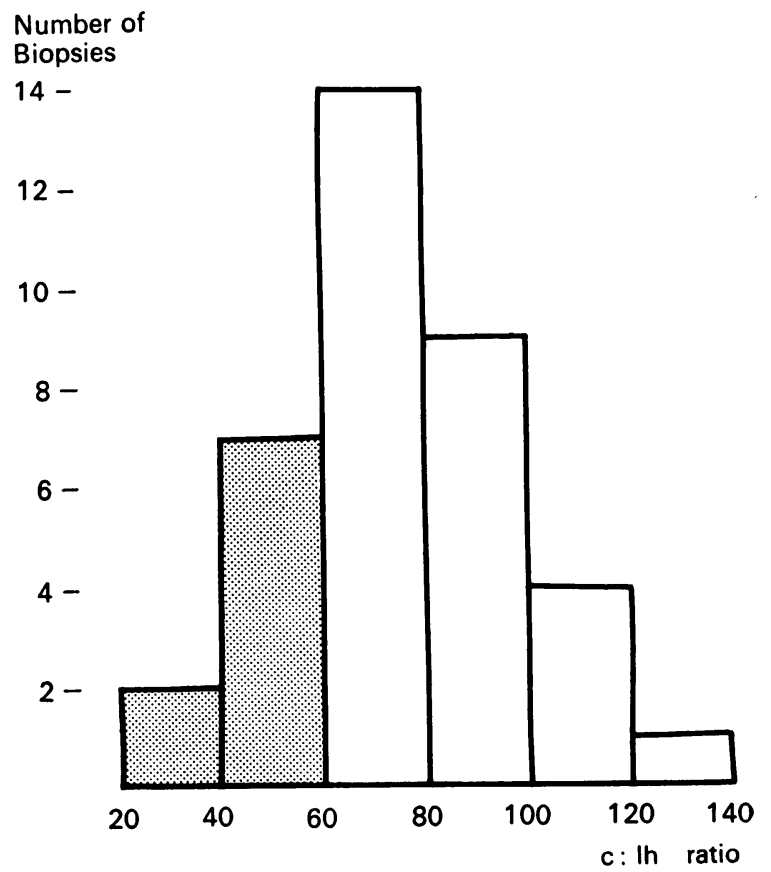

Fig 4 A histogram showing the normal distribution of c:lh ratios in the 37 control biopsies. The average age of the nine cases with c:lh ratios below 60 (corresponding to the shaded area) was $31.1 \mathrm{mth}$, whilst that of the remaining 28 cases was $65.9 \mathrm{mth}$. The difference between the two means is significant $(\mathrm{t}=2 \cdot 2 ; 0.05>\mathrm{P}>0.025)$. 


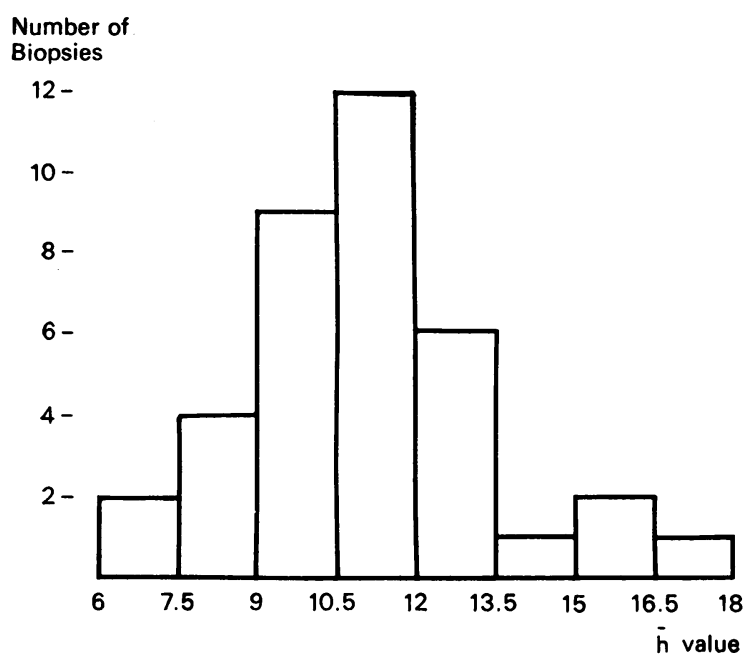

$\overline{\mathrm{h}}$ value

Fig 5
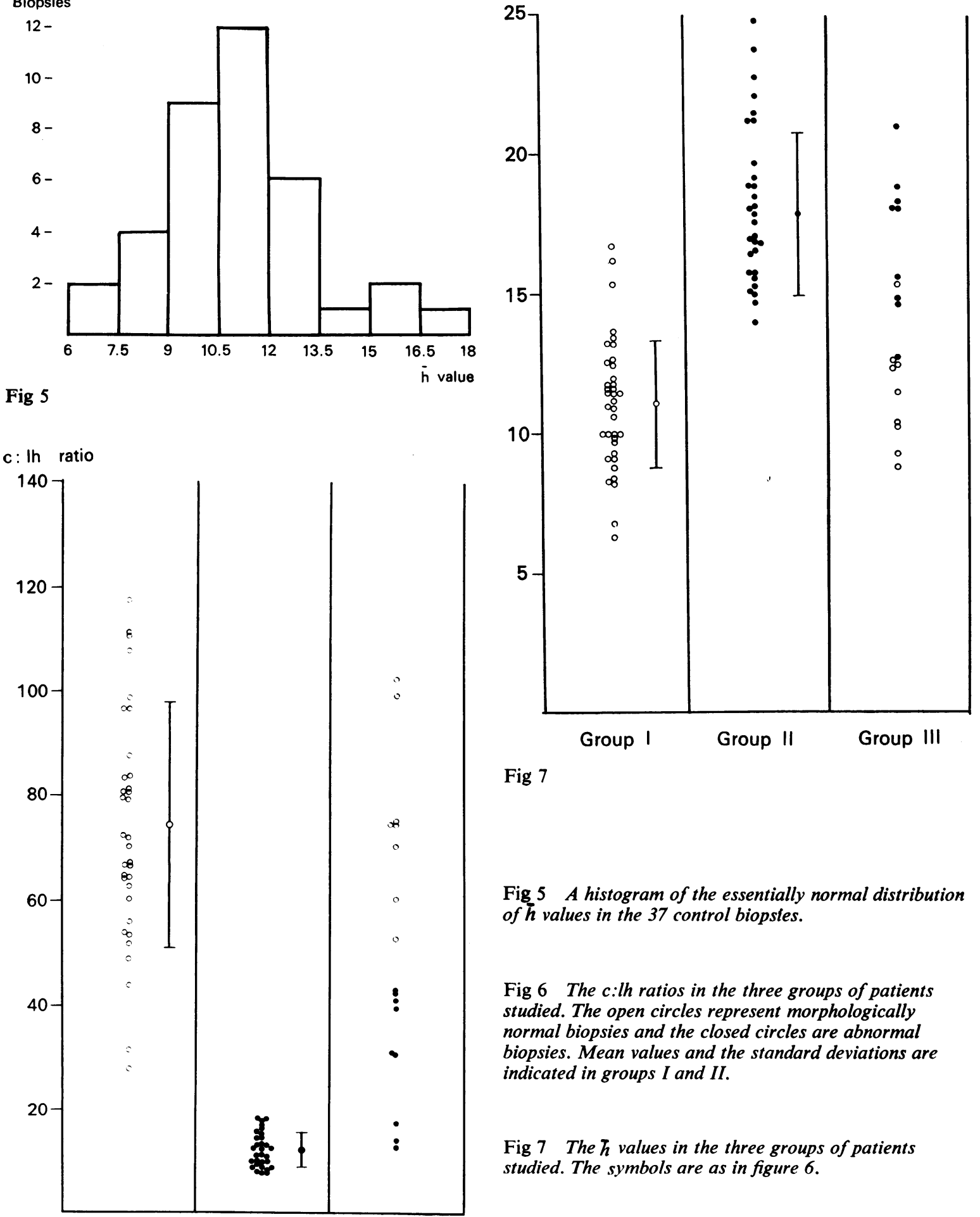

Fig 7

Fig 5 A histogram of the essentially normal distribution of $\bar{h}$ values in the 37 control biopsies.

Fig 6

Group I

Group II

Group III

Fig 6 The c:lh ratios in the three groups of patients studied. The open circles represent morphologically normal biopsies and the closed circles are abnormal biopsies. Mean values and the standard deviations are indicated in groups I and II.

Fig 7 The $h$ values in the three groups of patients studied. The symbols are as in figure 6. 


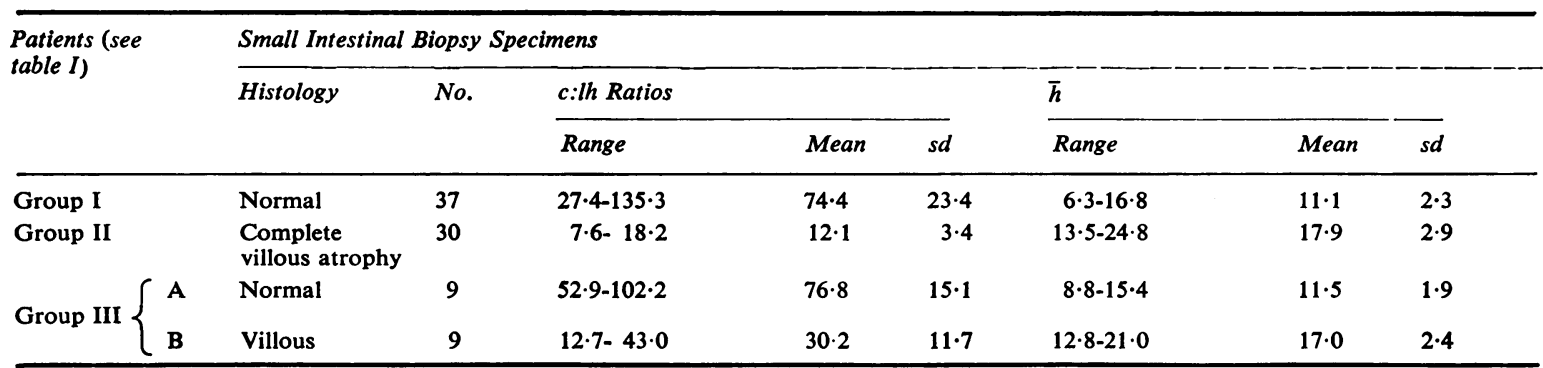

Table II Results of quantitative analyses of small intestinal biopsies from three groups of patients studied

discrepancy between our two observations in any of the biopsies examined was 13.9 for $c: l h$ and 2.6 for $\bar{h}$.

\section{Results}

These are set out in figs 4, 5, 6, and 7 and in Tables II and III.

The c:lh ratios of the biopsies from untreated coeliacs (group II) were invariably much less than those of controls (group I), and no overlap was observed between the two ranges. The $\bar{h}$ values, on the other hand, were significantly greater in group II biopsies.

The nine histologically abnormal biopsies from group IIIB had c:lh ratios in an intermediate range, the mean value being significantly less than that for the group I biopsies and significantly more than that for the group II biopsies. An overlap was noted between the $c:$ lh ratios for the abnormal biopsies in group IIIB and the lower end of the control range. A review of all the biopsies concerned confirmed the presence of unequivocal histological abnormalities in the group IIIB biopsies, quite apart from any blunting or fusion of villi. These included abnormalities of the surface epithelium together with an increase in inflammatory cells in the lamina propria (fig 8). No such abnormalities were seen in either of the two control biopsies involved in the overlap (fig 9). The $\bar{\hbar}$ values for the abnormal group IIIB biopsies were significantly greater than those for the group I biopsies, but did not differ significantly from those for the group II biopsies.

\begin{tabular}{|c|c|c|}
\hline & $t$ & $p$ \\
\hline $\begin{array}{l}\text { Differences between the n } \\
\text { ratios for biopsies in } \\
\text { group I and group II } \\
\text { group I and group IIIB } \\
\text { group II and group IIIB }\end{array}$ & $\begin{array}{c}13 \cdot 9 \\
5 \cdot 38 \\
7 \cdot 28\end{array}$ & $\begin{array}{l}<0.001 \\
<0.001 \\
<0.001\end{array}$ \\
\hline $\begin{array}{l}\text { Differences between the } n \\
\text { for biopsies in } \\
\text { group I and group II } \\
\text { group I and group IIIB } \\
\text { group II and group IIIB }\end{array}$ & $\begin{array}{c}10 \cdot 6 \\
6 \cdot 36 \\
0 \cdot 86\end{array}$ & $\begin{array}{l}<0.001 \\
<0.001 \\
0.5>P>0.4\end{array}$ \\
\hline
\end{tabular}

Table III Statistical analysis

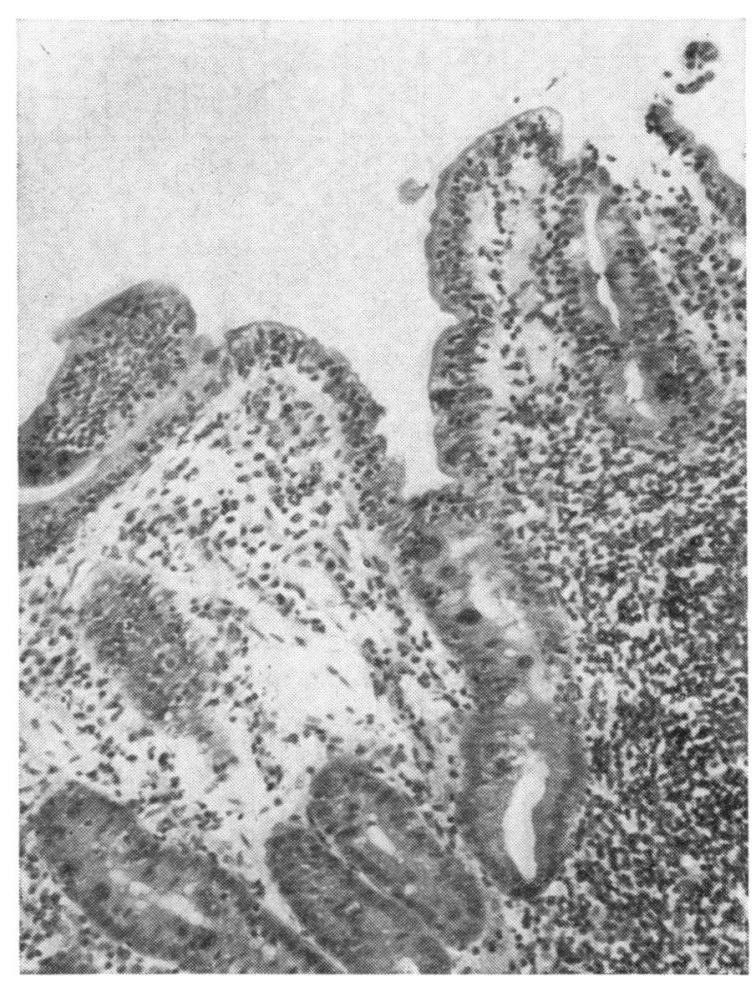

Fig 8 Abnormal biopsy from group III. Apart from marked blunting and fusion of the intestinal villi, there is in addition flattening of the surface epithelial cells, with disorderly arrangement of their nuclei and infiltration by lymphocytes between the epithelial cells. Chronic inflammatory cell infiltration of the lamina propria is excessive. $H E \times 15$.

\section{Discussion}

The pathological abnormalities found in small intestinal biopsy specimens are usually defined only in subjective terms (Shiner and Doniach, 1960; Watson, Paton, and Murray, 1965). There are, however, a number of advantages in assessing them quantitatively. Minor variations from normality can 


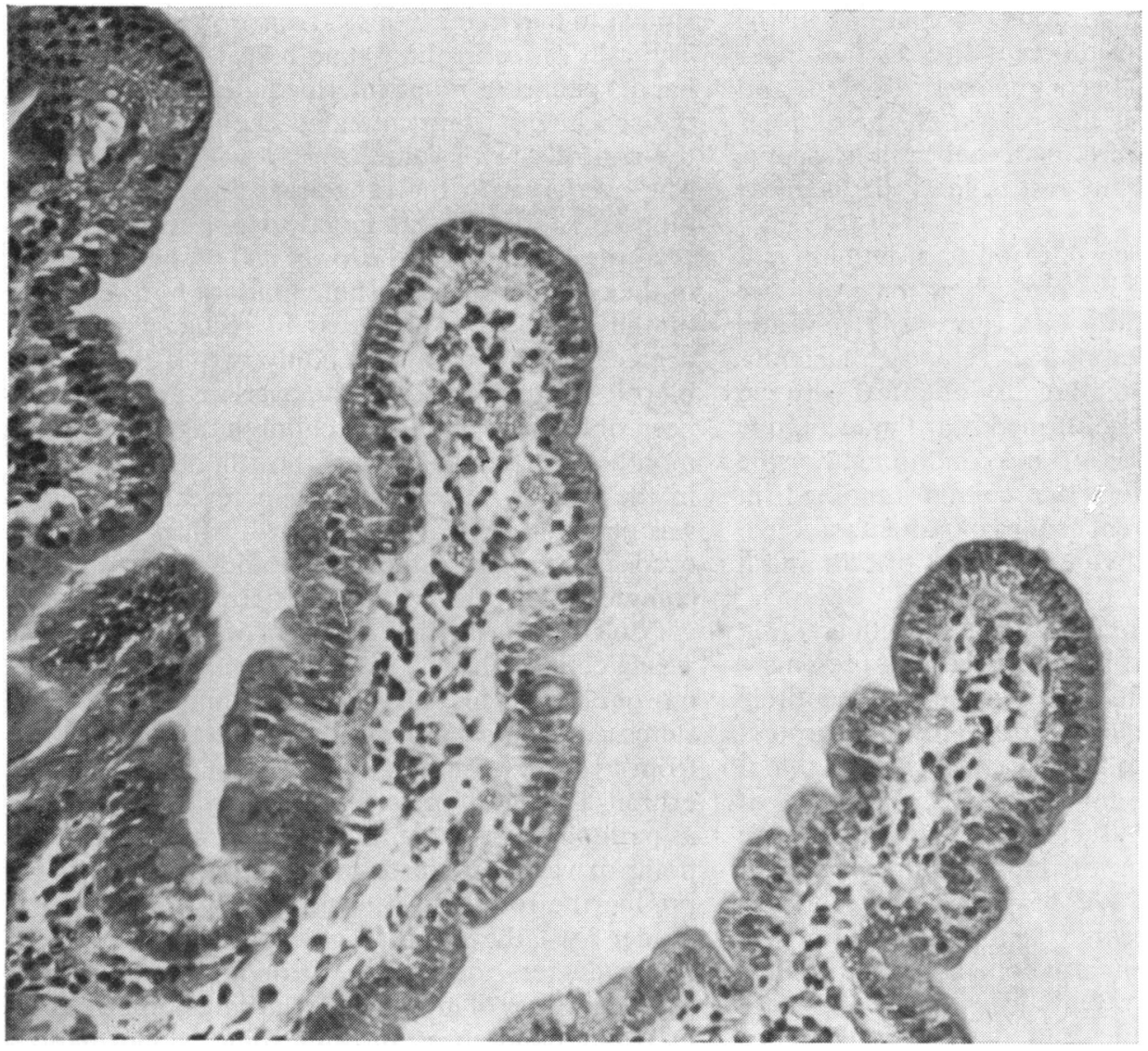

Fig 9 Intestinal biopsy from a young child (aged $19 \mathrm{mth}$ ) in the control group. The c:lh ratio is only 31.4 and $\bar{h}$ value 15.4 . Note the normal surface epithelium covering the villi. The cells are of normal height and the nuclei are arranged regularly along the basement membrane.

$H \& E \times 40$.

be determined with greater confidence, and objective comparisons can be made between biopsies obtained both from different individuals, or the same individuals at different times. For quantitative histological analysis to be valid, the method used must be accurate and reproducible, and a normal range of values adequately defined.

Dunnill and Whitehead (1972), in describing the technique for analysing small intestinal biopsies which we have followed, criticized other methods applied previously for this purpose which they regarded as inherently inaccurate. For a number of reasons they questioned the use of techniques for assessing villous atrophy which are based on linear measurements of villous height, mucosal thickness, or crypt depth (Rubin et al, 1960; Thurlbeck et al, 1960; Madanagopalan et al, 1965; Stewart et al, 1967). The decision as to where a villus ends and a crypt begins, which necessarily affects the measurement of both structures, is often quite arbitrary. The length of a villus cannot be measured accurately when it is flattened, branched, or not in an upright position. Furthermore, biopsies that lack a muscularis mucosae are liable to longitudinal stretching and may show separation and broadening of the villi, which results in a spurious reduction of their length. Such distortion also affects measurements of mucosal surface area based on the use of intersecting lines, unless, as in Dunnill and Whitehead's method, this measurement is related to mucosal volume. Accurate assessment of the biopsy appearances also depends on the adequacy of the specimen and its proper histological preparation (Rubin and Dobbins, 1965). Prompt and adequate fixation and careful processing and sectioning are required. Any quantitative technique is valueless if the sections are improperly orientated, since any degree of tangential cutting will affect the counts and make comparisons between biopsies meaningless. In addition, the level in the small intestine from which a biopsy is taken may be 
important in comparative studies. Variations in the mucosal appearances at different sites in the upper small intestine have been reported (Rubin and Dobbins, 1965) and for this reason all the biopsies in the present series were made under fluoroscopic control from the same site just beyond the ligament of Treitz.

In order to test the reproducibility of Dunnill and Whitehead's method in our own material, we determined independently $c: l h$ ratios and $\bar{h}$ values for each of the biopsies studied. The highly significant correlations and small scatter obtained between our two sets of results confirmed that the technique was reproducible under working conditions. For the purposes of comparing the counts obtained in biopsies from the different groups of patients studied, average values of our two estimations of $c: l h$ and $\bar{h}$ were used.

The definition of a range of values of $c: l h$ and $\bar{h}$ in normal small intestinal biopsy specimens presents a number of problems. Ideally, biopsies from entirely normal individuals should be studied for this purpose, but in practice, particularly in children, this is not possible. The use of intestinal mucosa taken at necropsy is also impracticable since even the freshest material obtained from this source is subject to autolytic changes. We have used for controls biopsies which appeared subjectively normal, obtained from children in whom adequate clinical investigation failed to reveal any evidence of malabsorption. These patients suffered from diarrhoea which was often intermittent in character, failure to thrive, or unexplained short stature. Small intestinal biopsies had been performed to exclude any possibility that they might have coeliac disease. Using the strictest criteria they could not be considered as entirely 'normal' but were the nearest practical alternative.

The $c: l h$ ratios and $\bar{h}$ values calculated for the control biopsies showed essentially normal distributions (figs 4 and 5). The c:lh ratios observed in the flat biopsies from the untreated coeliacs (group II) fell well below the range seen in the control biopsies, with no overlap between the two groups. This reflects a marked reduction in surface-tovolume ratios in the atrophic biopsies due to flattening of the villi. The $h$ values in the flat biopsies were significantly greater than those of the controls, although some overlap occurred between the two groups. This shows that, in general, the mucosal volume in the flat biopsies is actually increased.

The biopsies from the patients in group III included both histologically normal specimens, and biopsies showing varying degrees of villous atrophy. The $\bar{h}$ values in the nine abnormal biopsies in this group showed a significant increase over the controls similar to that in the biopsies from untreated coeliacs? The c:lh ratios in these nine biopsies, on the other: hand, spanned a range intermediate between that of the specimens from untreated coeliacs and that of the controls, with some overlap with both groups $\frac{\bar{\sigma}}{\overline{5}}$ The overlap with the range seen in the totally flaf biopsies is not of great practical importance. How? ever, the overlap with the lower end of the range seerp in the controls suggests some limitation in the value of the technique when used in recognizing minordegrees of villous atrophy. Only two of the controf biopsies were involved in the overlap, and both hac been obtained from young children (aged 15 and 19 months). Further analysis of the c:lh ratios observed in the rest of the control group revealed that this was part of a trend, the lower c:lh values tending to occur in younger children. It would appear that the. complexity of the villous pattern increases at कs varying rate during the first years of life so that some young children have a relatively 'immature' mucos侎 morphology. This suggestion is supported by the. stereoscopic appearances of small intestinal biopsies from young children which not uncommonly exhibit a 'ridged' pattern which might be regarded as pathological in an adult (fig 10). From a practicat point of view, provided one is cautious when intero preting the results in biopsies from young childres (under $2 \mathrm{yr}$ ), the $\mathrm{c}: \mathrm{lh}$ ratio gives a good indication of slight degrees of villous atrophy. Similarly on should be wary of interpreting the biopsy appearances in young children as showing minor abnormalities ('partial villous atrophy') purely on the villous pattern. Careful considerations should also be given to any abnormalities of the surface epitheliuns, particularly that covering the tips of the villi, and any excessive cellular infiltration of the laming propria. In the present study changes of this type

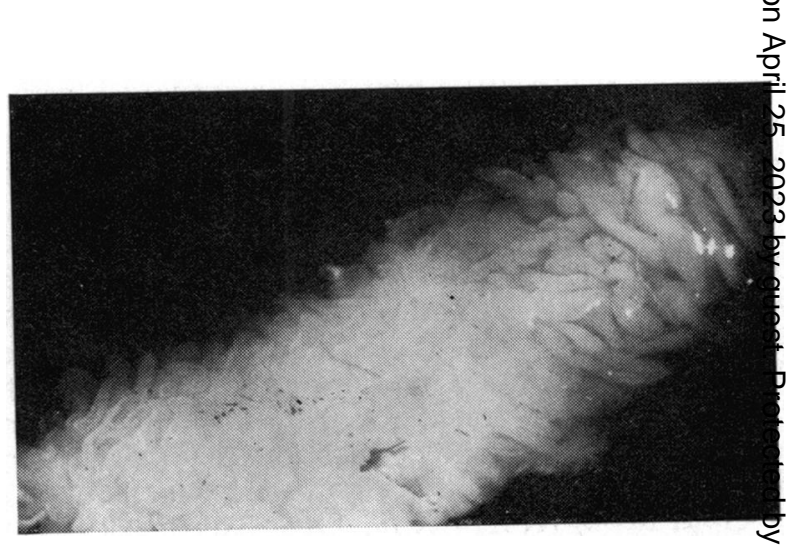

Fig 10 Dissecting microscope appearances of an intestinal biopsy from a young child, showing a ridged mucosal pattern. Histologically no morphological abnormalities are seen. 


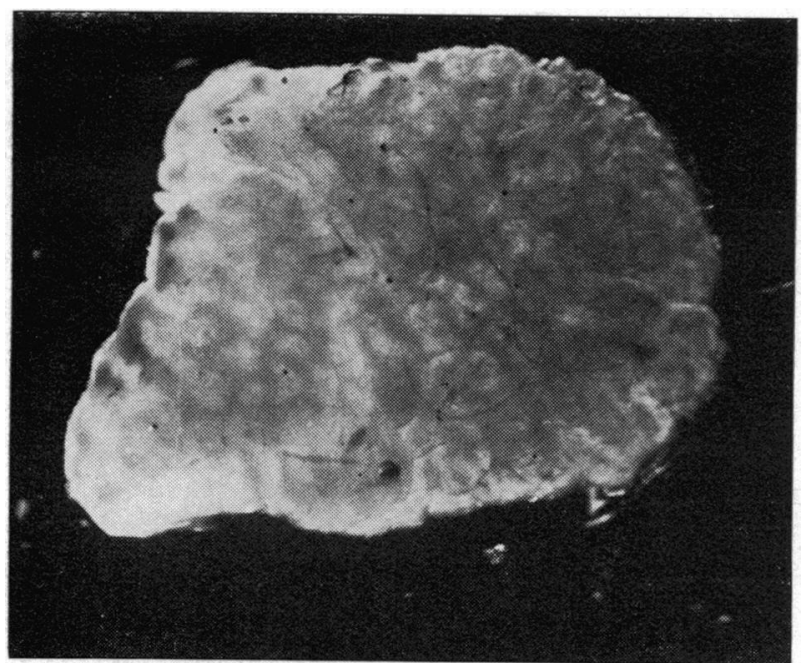

Fig 11 Dissecting microscope appearances of a flat intestinal biopsy from a child with untreated coeliac disease.

were lacking in the control biopsies but were present in all nine abnormal biopsies from group III.

Significant differences are apparent on comparing the numerical values for $c: l h$ and $\bar{h}$ in the various biopsies we have examined, with those obtained by Dunnill and Whitehead (1971) in apparently similar material. The c:lh ratios we have calculated tend to be higher and our $\bar{h}$ values lower. This is best explained if the number of 'hits' (h) obtained in our counts were, in general, slightly less. This may mean that the mucosal volume in adult biopsies is somewhat greater than in children, ie, that the difference is related merely to the source from which the biopsies were obtained, or it may reflect some small differences in methodology.

With regard to the histological diagnosis of coeliac disease in children, this study confirms that biopsies from untreated cases are almost invariably entirely flat showing a 'cobblestone' appearance with complete loss of villous pattern under the dissecting microscope and complete villous atrophy on histological sectioning (figs 11 and 12). All the biopsies from untreated coeliacs had $\mathrm{c}: \mathrm{lh}$ ratios well outside the range seen in the controls. Severe mucosal abnormalities of this nature are easily recognized by subjective means without recourse to quantitative techniques. However, as emphasized by Meeuwisse (1970), the proper diagnosis of coeliac disease requires at least two, and preferably three, biopsies in order to confirm the causal relationship between the mucosal lesion and exposure to dietary gluten. It is in following the changes in serial biopsies from the

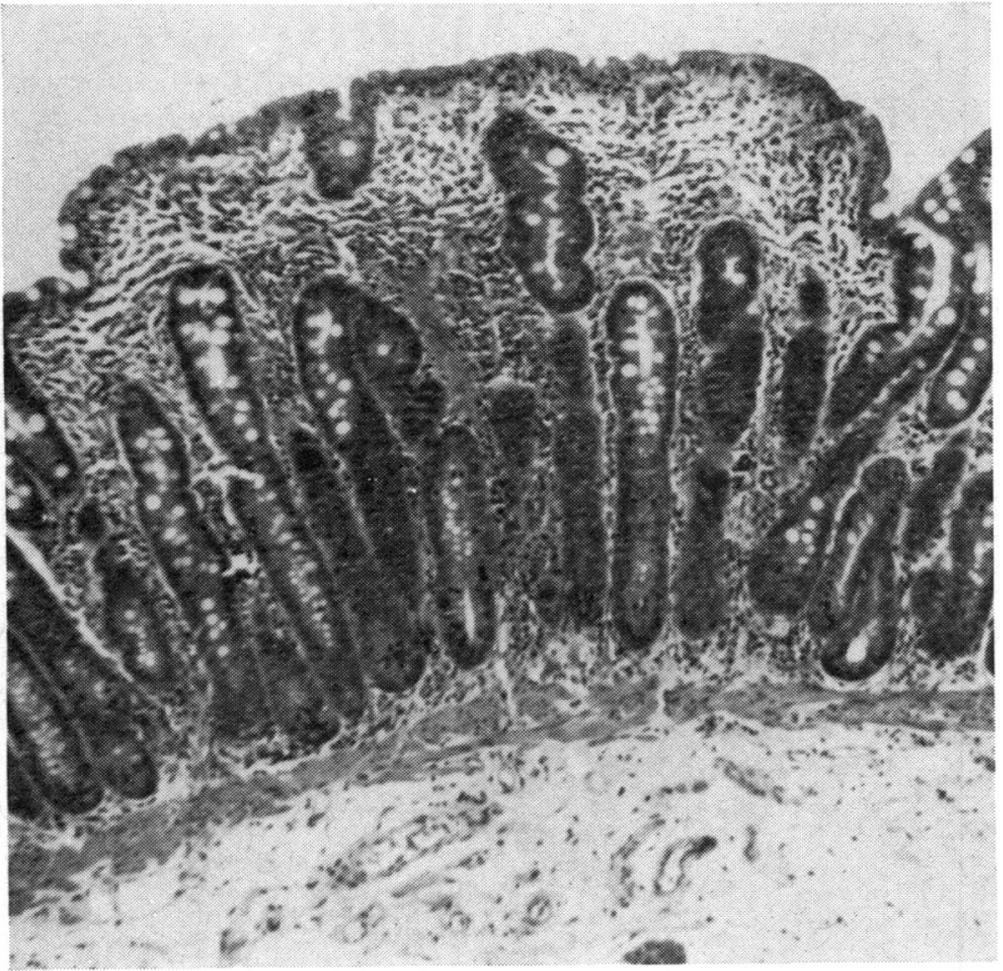

Fig 12 Complete villous atrophy in a mucosal biopsy from a child with untreated coeliac disease. $H \& E \times 15$. 
same patient that quantitation is most useful in that it allows truly objective comparisons to be made. In children with coeliac disease, the rate at which the mucosal morphology responds to dietary gluten exclusion, or the reintroduction of gluten after a period of withdrawal, varies quite considerably. Thus where serial biopsies are used to confirm the diagnosis histologically, intermediate degrees of mucosal abnormality (corresponding to 'partial villous atrophy' of varying severity) may be encountered. It is precisely in this situation that quantitation of the mucosal changes is most useful. In the present study only three biopsies with c:lh ratios in the 'intermediate' range were from children with coeliac disease. In all three instances biopsies were performed after a period of gluten withdrawal or after the reintroduction of gluten following a long period of exclusion.

\section{References}

Anderson, C. M. (1960). Histological changes in the duodenal mucosa in coeliac disease: reversibility during treatment with a wheat gluten free diet. Arch. Dis. Childh., 35, 419-427.

Anderson, C. M., Gracey, M., and Burke, V. (1972). Coeliac disease. Some still controversial aspects. Arch. Dis. Childh., 47, 292298.

Dunnill, M. S., and Whitehead, R. (1972). A method for the quantitation of small intestinal biopsy specimens. J. clin. Path., 25, 243246.
Harris, O. D., Cooke, W. T., Thompson, H., and Waterhouse, J. A. H. (1967). Malignancy in adult celiac disease and idiopathic steatorrhea. Amer. J. Med., 42, 899-912.

Madanagopalan, N., Shiner, M., and Rowe, B. (1965). Measurements of small intestinal mucosa obtained by peroral biopsy. Amer.J. Med., 38, 42-53.

Meeuwisse, G. W. (1970). Diagnostic criteria in coeliac disease. (Discussion, European Society for Paediatric Gastroenterology). Acta paediat. scand., 59, 461-463.

Rubin, C. E., Brandborg, L. L., Phelps, P. C., Taylor, H. C., Jr., Murray, C. V., Stemler, R., Howry, C., and Volwiler, W. (1960). Studies in celiac disease. Part 2. The apparent irreversibility of the proximal intestinal pathology in celiac disease. Gastroenterology, 38, 517-535.

Rubin, C. E., and Dobbins, W. O., III (1965). Peroral biopsy of the small intestine: a review of its diagnostic usefulness. Gastroenterology, 49, 676-697.

Shiner M. (1956). Duodenal biopsy. Lancet, 1, 17-19.

Shiner, M., and Doniach, I. (1960). Histopathologic studies in steatorrhea. Gastroenterology, 38, 419-440.

Stewart, J. S., Pollock, D. J., Hoffbrand, A. V., Mollin, D. L., and Booth, C. C. (1967). A study of proximal and distal intestinal structure and absorptive function in idiopathic steatorrhoea. Quart. J. Med., 36, 425-444.

Thurlbeck, W. M., Benson, J. A., Jr., and Dudley, H. R., Jr. (1960). The histopathologic changes of sprue and their significance. Amer. J. clin. Path., 34, 108-117.

Townley, R. R. W., and Barnes, G. L. (1973). Intestinal biopsy in childhood. Arch. Dis. Childh., 48, 480-482.

Watson, W. C., Paton, E., and Murray, D. (1965). Small bowel disease in rosacea. Lancet, 2, 47-50.

Whitehead, R. (1971). The interpretation and significance of morphological abnormalities in jejunal biopsies. J. clin. Path., 24, Suppl. (Roy. Coll. Path.), 5, 108-124.

Weibel, E. R. (1963). Principles and methods for the morphometric study of the lung and other organs. Lab. Invest., 12, 131-155.

Young, W. F., and Pringle, E. M. (1971). 110 children with coeliac disease, 1950-1969. Arch. Dis. Childh., 46, 421-436. 